Gut and Liver, Vol. 13, No. 1, January 2019, pp. 25-31

\title{
Effect of Abdominal Visceral Fat Change on the Regression of Erosive Esophagitis: A Prospective Cohort Study
}

\author{
Su Youn Nam ${ }^{1,2}$, Young-Woo Kim ${ }^{3}$, Bum Joon Park ${ }^{2}$, Kum Hei Ryu², and Hyun Boem Kim ${ }^{4}$ \\ ${ }^{1}$ Center for Gastric Cancer, Kyungpook National University Chilgok Hospital, School of Medicine, Kyungpook National University, Daegu, \\ ${ }^{2}$ Center for Cancer Prevention \& Detection, ${ }^{3}$ Center for Gastric Cancer, and ${ }^{4}$ Department of Diagnostic Radiology, National Cancer Center, \\ Goyang, Korea
}

See editorial on page 1.

Background/Aims: Although abdominal visceral fat has been associated with erosive esophagitis in cross-sectional studies, there are few data on the longitudinal effect. We evaluated the effects of abdominal visceral fat change on the regression of erosive esophagitis in a prospective cohort study. Methods: A total of 163 participants with erosive esophagitis at baseline were followed up at 34 months and underwent esophagogastroduodenoscopy and computed tomography at both baseline and follow-up. The longitudinal effects of abdominal visceral fat on the regression of erosive esophagitis were evaluated using relative risk (RR) and 95\% confidence intervals (Cls). Results: Regression was observed in approximately $49 \%$ of participants $(n=80)$. The 3rd (RR, $0.13 ; 95 \% \mathrm{Cl}, 0.02$ to 0.71 ) and 4th quartiles (RR, 0.07; 95\% $\mathrm{Cl}, 0.01$ to 0.38 ) of visceral fat at follow-up were associated with decreased regression of erosive esophagitis. The highest quartile of visceral fat change reduced the probability of the regression of erosive esophagitis compared to the lowest quartile (RR, 0.10; $95 \% \mathrm{Cl}, 0.03$ to 0.28). Each trend showed a dose-dependent pattern ( $p$ for trend $<0.001$ ). The presence of baseline Helicobacter pylori increased the regression of erosive esophagitis (RR, 2.40; $95 \% \mathrm{Cl}, 1.05$ to 5.48). Conclusions: Higher visceral fat at follow-up and a greater increase in visceral fat reduced the regression of erosive esophagitis in a dose-dependent manner. (Gut Liver 2019;13:25-31)

Key Words: Esophagitis; Intra-abdominal fat; Cohort studies

\section{INTRODUCTION}

The prevalence of gastroesophageal reflux disease (GERD) according to increase of obesity has been increasing over the past decades in Korea. ${ }^{1,2}$ Many previous studies demonstrated the association between obesity and GERD. ${ }^{3-5}$ Abdominal visceral fat contribute to GERD by mechanical disruption of the integrity of the gastroesophageal junction ${ }^{6}$ and metabolic effects such as increasing inflammatory cytokines and the risk of cardiovascular disease. ${ }^{7}$ We previously demonstrated that abdominal visceral fat was a better predictor of reflux esophagitis than body mass index (BMI). ${ }^{4}$ Recent cross-sectional studies also showed a strong relationship of abdominal visceral fat with erosive esophagitis $^{8}$ and Barrett's oesophagus. ${ }^{9}$ We firstly reported that high visceral fat and increase of visceral fat during follow-up induced new development of erosive esophagitis in a previous cohort study. ${ }^{10}$

However, there are no data the effect of visceral fat on the regression of erosive esophagitis even if weight gain increased the risk of erosive esophagitis. ${ }^{3}$ We therefore evaluated the longitudinal effects of visceral fat and the effect of its change on regression of erosive esophagitis.

\section{MATERIALS AND METHODS}

\section{Study population}

This is a prospective cohort study. A total of 1,765 patients who underwent endoscopy and abdominal fat computed tomography (CT) from February to November 2008 and underwent follow-up CT and completed questionnaires from May 2010 to August 2013 (Fig. 1). We excluded those who used proton pump inhibitor within 4 weeks, did not undergo follow-up endoscopy

\footnotetext{
Correspondence to: Su Youn Nam

Center for Gastric Cancer, Kyungpook National University Chilgok Hospital, School of Medicine, Kyungpook National University, 807 Hoguk-ro, Buk-gu, Daegu 41404, Korea

Tel: +82-53-200-2610, Fax: +82-53-200-2028, E-mail: nam20131114@gmail.com

Received on December 9, 2017. Revised on February 15, 2018. Accepted on February 17, 2018. Published online June 22, 2018

pISSN 1976-2283 eISSN 2005-1212 https://doi.org/10.5009/gnl17553

@ This is an Open Access article distributed under the terms of the Creative Commons Attribution Non-Commercial License (http://creativecommons.org/licenses/by-nc/4.0) which permits unrestricted non-commercial use, distribution, and reproduction in any medium, provided the original work is properly cited.
} 
or the Helicobacter pylori test $(\mathrm{n}=99)$. And we excluded absence of erosive esophagitis at baseline $(n=1,503)$. Well trained clinical research coordinators interviewed participants and completed all questionnaires. The National Cancer Center Institutional Review Board approved the study (NCCNCS-10331), and all participants provided written informed consent for the use of clinical data for research.

\section{Endoscopy}

Participants underwent endoscopy using a flexible endoscope (Q260; Olympus Optical, Tokyo, Japan) under conscious sedation. ${ }^{4}$ We investigated the gastroesophageal junction before inflation of the stomach. The severity of erosive esophagitis was classified from A to D according to the Los Angeles (LA) classification system. ${ }^{11}$ Endoscopic evaluation of reflux esophagitis was previously validated by four gastroenterologists ${ }^{4}$ and they also underwent follow-up endoscopic examination. Rapid urease test (Pronto Dry; Medical Instruments, Solothurn, Switzerland) was performed to evaluate $H$. pylori using biopsy specimen acquired at the greater curvature of the body.

\section{Measurement of obesity}

Weight and height were measured by X-SCAN PLUS II (Jawon Medical Co., Gyeongsan, Korea), and BMI was calculated as weight divided by height squared $\left(\mathrm{kg} / \mathrm{m}^{2}\right)$. Waist circumferences were measured at the midpoint between the lower borders of the rib cage and upper pole of iliac crest.

Abdominal fat was detected using 64-multidetector CT (Brilliance 64; Philips, Best, the Netherlands). ${ }^{4}$ In summary, contiguous 5-mm slices were acquired, and fat volume was calculated using 20 slices covering $100 \mathrm{~mm}$ located $50 \mathrm{~mm}$ above to 50 $\mathrm{mm}$ below the umbilicus. Abdominal fat compartments were manually traced in each image, segmentation of the 20 slices was automatically reconstructed, and volume $\left(\mathrm{cm}^{3}\right)$ was estimated using software (Extended Brilliance Workspace version 3.5; Philips) that electronically determined area by setting attenuation values for a region of interest within a range of 25 to -175 Hounsfield units. Visceral fat was defined as intra-abdominal fat bound by parietal peritoneum or transversalis fascia, excluding the vertebral column and paraspinal muscles. The subcutaneous fat volume was acquired by subtracting visceral fat volume from total adipose tissue volume.

\section{Statistical analysis}

We performed a Pearson chi-square test or independent ttest to evaluate the difference of demographic characteristics, clinical factors, and obesity indices between persistence and regression of erosive esophagitis. Fat volumes were categorized into quartiles based on total baseline participants $(n=1,765)$ for further analysis. The effects of visceral fat volume and cofactors on regression of erosive esophagitis were estimated with relative risk (RR) and 95\% confidence intervals (CIs) using regression analysis. Follow-up visceral fat and change of visceral fat (follow-up-baseline) were analyzed by t-test to evaluate their relationships with regression of erosive esophagitis. To confirm the factors associated with regression of esophagitis, we performed multivariate regression analysis on the following combinations of confounding factors and visceral fat: (1) baseline confounding factors and quartile of baseline visceral fat; (2) follow-up confounding factors and quartile of follow-up visceral fat; and (3) follow-up confounding factors and quartile of visceral fat change.

All statistical analyses were performed using STATA software version 12 (College Station, TX, USA). All statistical tests were two-sided, and $\mathrm{p}<0.05$ was considered statistically significant.

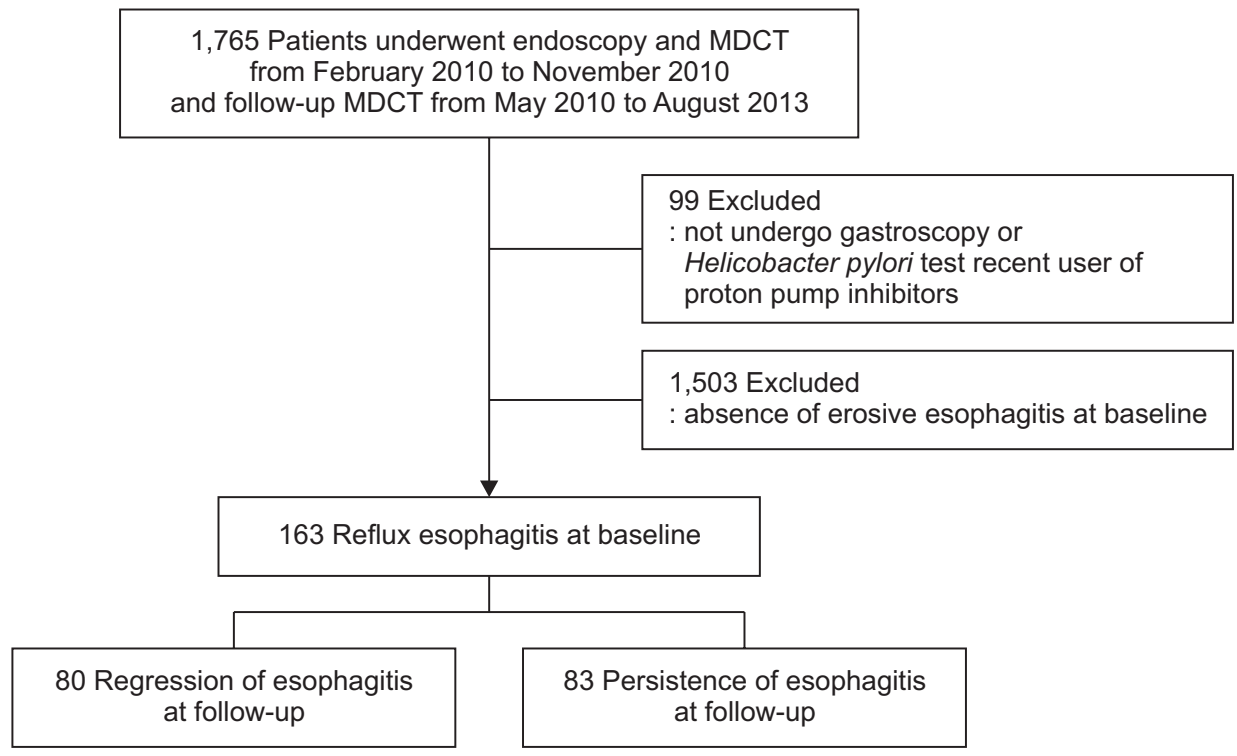

Fig. 1. Study flowchart. MDCT, multi-detector computed tomography. 


\section{RESULTS}

\section{Characteristics of participants at baseline and follow-up}

A total of 163 participants met the final inclusion criteria at follow-up from May 2010 to August 2013 (Fig. 1). Baseline mean age was 51.4 years (standard deviation, 8.2 years) and male sex was 92\% $(\mathrm{n}=150)$. Baseline $H$. pylori infection rate was 22.7\% (n=37) (Table 1). The mean follow-up duration was

Table 1. Baseline Characteristics of Participants

\begin{tabular}{|c|c|c|c|}
\hline Characteristic & Persistent of esophagitis $(\mathrm{n}=83)^{*}$ & Regression of esophagitis $(\mathrm{n}=80)^{*}$ & p-value ${ }^{\dagger}$ \\
\hline Male sex & $80(96.4)$ & $70(87.5)$ & 0.036 \\
\hline Age, yr & $50.5 \pm 7.5$ & $52.4 \pm 8.8$ & 0.146 \\
\hline \multicolumn{4}{|l|}{ Obesity index } \\
\hline BMI, $\mathrm{kg} / \mathrm{m}^{2}$ & $26.1 \pm 3.1$ & $24.8 \pm 2.8$ & 0.006 \\
\hline Waist circumference, $\mathrm{cm}$ & $90.9 \pm 7.3$ & $88.3 \pm 7.7$ & 0.028 \\
\hline Visceral fat volume, $\mathrm{cm}^{3}$ & $1,237 \pm 495$ & $1,131 \pm 510$ & 0.182 \\
\hline Total fat volume, $\mathrm{cm}^{3}$ & $2,953 \pm 878$ & $2,843 \pm 847$ & 0.417 \\
\hline \multicolumn{4}{|l|}{ Demographic findings } \\
\hline Hypertension & $18(21.7)$ & $23(28.7)$ & 0.299 \\
\hline Diabetes & $3(3.6)$ & $8(10.0)$ & 0.104 \\
\hline Use of lipid lowering drugs & $1(1.2)$ & $6(7.5)$ & 0.047 \\
\hline Use of aspirin & $13(15.7)$ & $10(12.5)$ & 0.562 \\
\hline Current smoking & $46(55.4)$ & $31(38.7)$ & 0.033 \\
\hline Current alcohol consumption & 70 (84.3) & $59(73.7)$ & 0.096 \\
\hline \multicolumn{4}{|l|}{ Concomitant endoscopic findings } \\
\hline Presence of Helicobacter pylori & $13(15.8)$ & $24(30.4)$ & 0.029 \\
\hline Hiatal hernia & $11(13.2)$ & $7(8.7)$ & 0.359 \\
\hline Presence of atrophic gastritis & 17 (20.5) & $18(22.5)$ & 0.754 \\
\hline
\end{tabular}

Data are presented as number $(\%)$ or mean \pm SD.

BMI, body mass index.

*Erosive esophagitis refers to reflux esophagitis, Los Angeles classification grade A to D; ${ }^{\dagger}$ p-values were derived from a t-test or chi-square test.

Table 2. Follow-up Characteristics of Participants

\begin{tabular}{|c|c|c|c|}
\hline Characteristic & Persistent of esophagitis $(\mathrm{n}=83)^{*}$ & Regression of esophagitis $(\mathrm{n}=80)^{*}$ & p-value ${ }^{\dagger}$ \\
\hline Follow-up duration, mo & $33.9 \pm 10.5$ & $33.7 \pm 10.6$ & 0.914 \\
\hline \multicolumn{4}{|l|}{ Obesity indexes at follow-up } \\
\hline BMI, $\mathrm{kg} / \mathrm{m}^{2}$ & $26.0 \pm 2.7$ & $24.6 \pm 2.9$ & 0.002 \\
\hline Visceral fat volume, $\mathrm{cm}^{3}$ & $1,424 \pm 503$ & $1,118 \pm 440$ & $<0.001$ \\
\hline Total fat volume, $\mathrm{cm}^{3}$ & $3,202 \pm 853$ & $2,812 \pm 775$ & 0.003 \\
\hline \multicolumn{4}{|c|}{ Obesity index change (follow-up baseline) } \\
\hline BMI, $\mathrm{kg} / \mathrm{m}^{2}$ & $-0.09 \pm 1.76$ & $-0.16 \pm 0.83$ & 0.744 \\
\hline Visceral fat volume, $\mathrm{cm}^{3}$ & $187 \pm 317$ & $-13 \pm 255$ & $<0.001$ \\
\hline Total fat volume, $\mathrm{cm}^{3}$ & $249 \pm 432$ & $-31 \pm 329$ & $<0.001$ \\
\hline \multicolumn{4}{|l|}{ Demographic findings } \\
\hline Current smoking & $41(49.4)$ & $25(31.3)$ & 0.015 \\
\hline Current alcohol consumption & 65 (78.3) & $51(63.7)$ & 0.040 \\
\hline \multicolumn{4}{|l|}{ Concomitant findings } \\
\hline Presence of Helicobacter pylori & $10(12.1)$ & 15 (18.8) & 0.235 \\
\hline Hiatal hernia & $15(18.1)$ & $8(10.0)$ & 0.139 \\
\hline
\end{tabular}

Data are presented as mean \pm SD or number $(\%)$.

BMI, body mass index.

*Esophagitis refers to reflux esophagitis, Los Angeles classification grade A to D; ${ }^{\dagger} \mathrm{p}$-values were derived from a t-test or chi-square test. 
33.7 months. Regression of erosive esophagitis was noted in 83 persons. Male sex, higher BMI and waist circumference, current smoker, and absence of $H$. pylori at baseline was associated with persistent erosive esophagitis (Table 1). Even if there was no statistical difference, current alcohol consumption in the esophagitis persistent group was higher than the esophagitis regression group.

Overall visceral fat volume $\left(1,184 \mathrm{~cm}^{3}\right.$ vs $\left.1,273 \mathrm{~cm}^{3}\right)$ and total fat volume $\left(2,899 \mathrm{~cm}^{3}\right.$ vs $\left.3,010 \mathrm{~cm}^{3}\right)$ increased at followup, whereas overall BMI at follow-up was nearly not changed. Overall infection rate of $H$. pylori markedly decreased at followup (22.6\% vs $15.3 \%)$.

\section{Effects of visceral fat on the regression of erosive esoph- agitis}

Whereas baseline visceral fat had no association with regression of erosive esophagitis, lower visceral fat at follow-up was noted in the regression group comparing to persistent esophagitis group (Tables 1 and 2). Whereas visceral fat decreased in the regression group $\left(-13 \mathrm{~cm}^{3}\right), 187 \mathrm{~cm}^{3}$ of visceral fat increased in persistent esophagitis group (Table 2). In addition, lower quartile of follow-up visceral fat and visceral fat change were associated with regression of erosive esophagitis (Table 2).

When adjusted for baseline visceral fat and cofactors, baseline visceral fat had no effect on the regression of erosive esophagitis (Table 3). The 3rd and 4th quartile of follow-up visceral fat decreased the regression of erosive esophagitis when adjusted for follow-up visceral fat and cofactors (Table 3). The effect of follow-up visceral fat on regression of erosive esophagitis was dose dependent pattern ( $p$ for trend <0.001) (Fig. 2A). When adjusted for change of visceral fat and follow-up cofactors, the highest quartile of visceral fat change decreased the regression of erosive esophagitis (Table 3). Its trend was also dose-dependent pattern ( $\mathrm{p}$ for trend $<0.001$ ) (Fig. 2B).

The presence of baseline $H$. pylori increased the regression of erosive esophagitis (adjusted odds ratio, 2.40; 95\% CI, 1.05 to 5.48). Other factors had no statistical significance.

\section{DISCUSSION}

To our knowledge, this is the first report to evaluate the effect of visceral fat change on the regression of erosive esophagitis. In this prospective cohort, higher visceral fat at follow-up and greater increase of visceral fat decreased the regression of erosive esophagitis with does-dependent pattern. Regression of erosive esophagitis was related with baseline $H$. pylori status but it had no association with follow-up H. pylori in this study.

In this adjusted analysis, only higher visceral fat at follow-

Table 3. Effect of Visceral Fat on the Regression of Erosive Esophagitis

\begin{tabular}{|c|c|c|c|c|}
\hline & $\begin{array}{l}\text { Persistent esophagitis } \\
\qquad(\mathrm{n}=83)\end{array}$ & $\begin{array}{l}\text { Regression of esophagitis } \\
\qquad(\mathrm{n}=80)\end{array}$ & RR $(95 \%$ CI) & p-value \\
\hline \multicolumn{5}{|l|}{ Quartile of baseline visceral fat* } \\
\hline 1st quartile $(<604)$ & $6(7.2)$ & $12(15.0)$ & 1 & \\
\hline 2nd quartile $(\geq 604,<921)$ & $15(18.1)$ & $20(25.0)$ & $0.78(0.21-2.90)$ & 0.71 \\
\hline 3rd quartile $(\geq 921,<1,239)$ & $25(30.1)$ & $19(23.8)$ & $0.58(0.16-2.13)$ & 0.42 \\
\hline 4th quartile $(\geq 1,239)$ & $37(44.6)$ & $29(36.2)$ & $0.43(0.12-1.53)$ & 0.19 \\
\hline Trend for quartile & & & $0.77(0.55-1.10)$ & 0.15 \\
\hline \multicolumn{5}{|l|}{ Quartile of follow-up visceral fat ${ }^{\dagger}$} \\
\hline 1st quartile $(<684)$ & $2(2.4)$ & $15(18.8)$ & 1 & \\
\hline 2nd quartile $(\geq 684,<1,036)$ & $13(15.7)$ & $21(26.2)$ & $0.22(0.04-1.21)$ & 0.08 \\
\hline 3rd quartile $(\geq 1,036,<1,388)$ & $26(31.3)$ & $22(27.5)$ & $0.13(0.02-0.71)$ & 0.02 \\
\hline 4 th quartile $(\geq 1,388)$ & $42(50.6)$ & $22(27.5)$ & $0.07(0.01-0.38)$ & 0.002 \\
\hline Trend for quartile & & & $0.50(0.34-0.73)$ & $<0.001$ \\
\hline \multicolumn{5}{|l|}{ 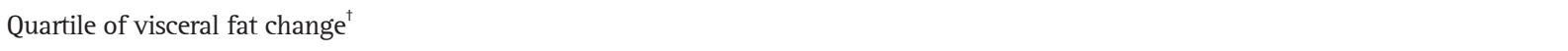 } \\
\hline 1st quartile $(<-44)$ & $17(20.5)$ & $32(40.0)$ & 1 & \\
\hline 2nd quartile ( $\geq-44,<102)$ & $15(18.1)$ & $20(25.0)$ & $0.64(0.24-1.71)$ & 0.37 \\
\hline 3rd quartile $(\geq 102,<250)$ & $11(13.2)$ & $19(23.8)$ & $0.67(0.23-1.95)$ & 0.46 \\
\hline 4th quartile ( $\geq 250$ ) & 40 (48.2) & $9(11.2)$ & $0.10(0.03-0.28)$ & $<0.001$ \\
\hline Trend for quartile & & & $0.55(0.41-0.75)$ & $<0.001$ \\
\hline
\end{tabular}

Data are presented as number (\%). Quartiles were determined based on total participants at baseline $(1,765)$.

$\mathrm{RR}$, relative ratio; CI, confidence interval.

*Adjusted for baseline confounding factors (age, sex, smoking, drinking, Helicobacter pylori, and hiatal hernia), follow-up duration (yr), and baseline obesity index; ${ }^{\dagger}$ Adjusted for confounding factors at follow-up (age, sex, smoking, drinking, H. pylori, and hiatal hernia), follow-up duration (yr), and obesity index at follow-up. 
A

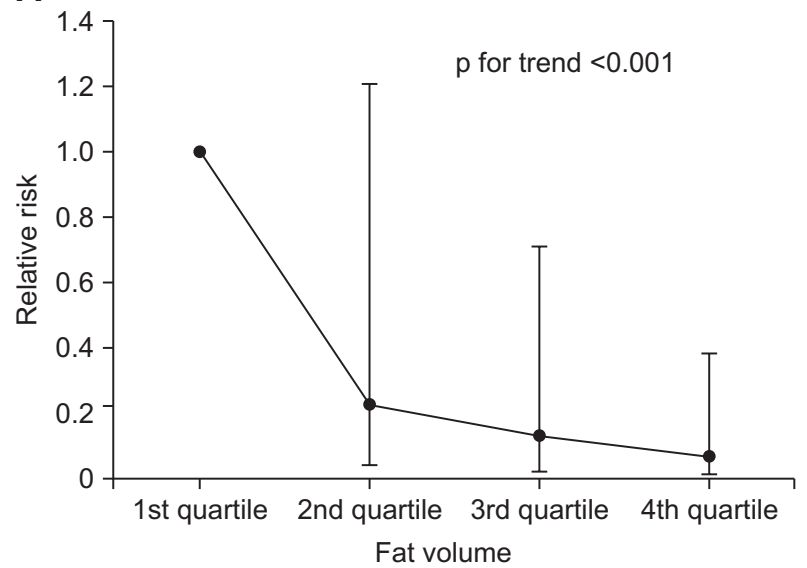

B

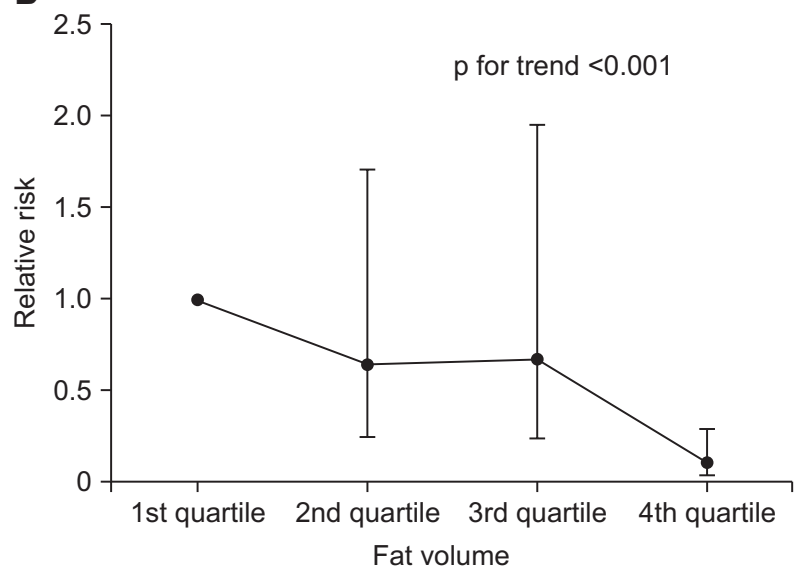

Fig. 2. Relative risk of regression of erosive esophagitis. (A) Relative risk (with 95\% confidence interval) of regression of erosive esophagitis by quartile of visceral fat volume at follow-up. (B) Relative risk (with 95\% confidence interval) of regression of erosive esophagitis by quartile of visceral fat volume change.

up, not baseline visceral fat, decreased the regression of erosive esophagitis. These results suggest that regression of erosive esophagitis depends on follow-up visceral fat. Greater increase of visceral fat decreased the regression of erosive esophagitis. These results suggest that reduction of visceral fat can induce regression of erosive esophagitis. Furthermore, all their associations were dose-dependent pattern.

Several hypotheses have been proposed to explain how abdominal obesity induce GERD. Abdominal visceral fat increases intragastric pressure and mechanically disrupts integrity of gastroesophageal junction and can induce acid reflux and play a significant role in GERD. ${ }^{6}$ Abdominal visceral fat also increases inflammatory cytokines ${ }^{12,13}$ and may accelerate the esophageal inflammation. In our previous study, abdominal visceral fat volume was a better predictor of erosive esophagitis than BMI or waist circumference in both men and women. ${ }^{4}$ Another crosssectional studies also suggested the effect of abdominal visceral fat on erosive esophagitis. ${ }^{814-16}$ Studies to evaluate the longitudinal effect of visceral fat on development or regression of esophagitis are very rare. Only one previous study showed that baseline visceral fat, follow-up visceral fat, and high increment of visceral fat increased the risk of new development of erosive esophagitis. $^{10}$

Baseline visceral fat had no association with regression of erosive esophagitis, whereas higher baseline BMI was associated with regression of erosive esophagitis. Low BMI may be a predictor of regression of esophagitis. Overall visceral and total fat volume increased during 33.7 months follow-up. This is similar to our previous results that visceral fat increased according to aging. In our previous study, $14 \mathrm{~cm}^{3}$ of visceral fat volume increased by 1 year increase of age. ${ }^{10}$ BMI had a little change between baseline and follow-up. BMI represents general body mass including fat, muscle, bone, major organs, and others, whereas visceral fat volume measured by multi-detector com- puted tomography (MDCT) represents pure abdominal visceral fat volume. Therefore, even if visceral fat increases by aging, the range of BMI change looks be small.

$H$. pylori infection rate remarkably decreased at follow-up comparing to baseline because many persons received $H$. pylori eradication treatment after baseline examination. Regression of erosive esophagitis was related with baseline $H$. pylori status but it had no association with follow-up $H$. pylori status in this study. In our previous study, $H$. pylori infection had an inverse relationship with erosive esophagitis and $H$. pylori eradication increased the risk of erosive esophagitis to the level of $H$. pylorinegative individuals. ${ }^{17}$ Even if male sex was lower in regression group of erosive esophagitis, sex had no association with regression of esophagitis in adjusted analysis. Men have higher visceral fat volume and more frequent smoker comparing to women, thereby look less regression of erosive esophagitis. Male sex itself looks no contributing factors of less regression of erosive esophagitis. Baseline current smoker was higher in persistent esophagitis group in unadjusted analysis. Baseline current drinker was higher in persistent esophagitis group even if there was no statistical significance. Statistical insignificance may be due to small number of patients in this study. Age, chronic disease such as hypertension and diabetes, and medication had no effect on the regression of erosive esophagitis.

This study has several strengths. The first, it evaluates the effects of visceral fat and its change on the regression of erosive esophagitis in a prospective cohort. To our knowledge, this is the first study that evaluates the longitudinal effect of visceral fat on the regression of erosive esophagitis. Second, data quality of questionnaires used in this study was high. ${ }^{4}$ Erosive esophagitis was objectively evaluated with endoscopy and classified by LA classification. Well trained clinical research coordinators interviewed the participants. The third, abdominal visceral fat volume was measured using a MDCT, which has a high degree 
of validity and reproducibility in estimating abdominal adipose tissue. $^{4,18}$

Nevertheless, this study also had several limitations. First, although the radiation dose used in this study was much lower than the dose used with conventional CT, the use of CT for measuring abdominal fat may be limited because of the risk of radiation exposure. Second, study population was homogenous Korean. For generalizability, external validation in other center or other race need in the future. Third, patients with erosive esophagitis at baseline are most men and sample size was relatively small, thereby we did not analyze sex-specific effect. Finally, we performed rapid urease test using single gastric tissue. Even if positive rate of rapid urease test using tissue from greater curvature of body was highest in our unpublished pilot study, rapid urease test using singe gastric tissue has a potential risk of false negativity.

In conclusion, higher visceral fat volume at follow-up and greater increase of visceral fat volume decreased regression of erosive esophagitis with dose-dependent pattern in a longitudinal setting. Therefore, reduction of abdominal visceral fat may induce regression of erosive esophagitis.

\section{CONFLICTS OF INTEREST}

No potential conflict of interest relevant to this article was reported.

\section{ACKNOWLEDGEMENTS}

This study was supported by grants (NCC 0810200 and NCC1110221-1,2,3) from the National Cancer Center, Korea. The funding source had no role in the design or conduct of the study, analysis, or interpretation of the data, or the preparation, or approval of the manuscript. The funding source did have a role in the collection of the questionnaires and was financially responsible for the abdominal multi-detector computed tomography.

Guarantor of the article: S.Y.N.

Author Contributions: S.Y.N. had full access to all of the data in the study and takes responsibility for the integrity of the data and the accuracy of the data analysis. S.Y.N. contributed to the study concept and design. S.Y.N., K.H.R., and B.J.P. performed endoscopy. S.Y.N. analyzed and interpreted data. H.B.K. contributed to the computed tomography to get abdominal fat volume. S.Y.N. and Y.W.K. contributed to the preparation of the grants. S.Y.N., Y.W.K., K.H.R., B.J.P., and H.B.K. participated in the writing of the manuscript. All authors have read and approved the paper.

\section{REFERENCES}

1. Kim N, Lee SW, Cho SI, et al. The prevalence of and risk factors for erosive oesophagitis and non-erosive reflux disease: a nationwide multicentre prospective study in Korea. Aliment Pharmacol Ther 2008;27:173-185.

2. Cho YS, Choi MG, Jeong JJ, et al. Prevalence and clinical spectrum of gastroesophageal reflux: a population-based study in Asan-si, Korea. Am J Gastroenterol 2005;100:747-753.

3. Nam SY, Choi IJ, Nam BH, Park KW, Kim CG. Obesity and weight gain as risk factors for erosive oesophagitis in men. Aliment Pharmacol Ther 2009;29:1042-1052.

4. Nam SY, Choi IJ, Ryu KH, Park BJ, Kim HB, Nam BH. Abdominal visceral adipose tissue volume is associated with increased risk of erosive esophagitis in men and women. Gastroenterology 2010;139:1902-1911.e2.

5. Corley DA, Kubo A, Zhao W. Abdominal obesity, ethnicity and gastro-oesophageal reflux symptoms. Gut 2007;56:756-762.

6. Pandolfino JE, El-Serag HB, Zhang Q, Shah N, Ghosh SK, Kahrilas PJ. Obesity: a challenge to esophagogastric junction integrity. Gastroenterology 2006;130:639-649.

7. Calabro P, Yeh ET. Intra-abdominal adiposity, inflammation, and cardiovascular risk: new insight into global cardiometabolic risk. Curr Hypertens Rep 2008;10:32-38.

8. Matsuzaki J, Suzuki H, Kobayakawa M, et al. Association of visceral fat area, smoking, and alcohol consumption with reflux esophagitis and Barrett's esophagus in Japan. PLoS One 2015;10:e0133865.

9. El-Serag HB, Hashmi A, Garcia J, et al. Visceral abdominal obesity measured by CT scan is associated with an increased risk of Barrett's oesophagus: a case-control study. Gut 2014;63:220-229.

10. Nam SY, Kim YW, Park BJ, et al. Effect of abdominal visceral fat on the development of new erosive oesophagitis: a prospective cohort study. Eur J Gastroenterol Hepatol 2017;29:388-395.

11. Armstrong D, Bennett JR, Blum AL, et al. The endoscopic assessment of esophagitis: a progress report on observer agreement. Gastroenterology 1996;111:85-92.

12. Bergman RN, Kim SP, Hsu IR, et al. Abdominal obesity: role in the pathophysiology of metabolic disease and cardiovascular risk. Am J Med 2007;120(2 Suppl 1):S3-S8.

13. Nam SY, Choi IJ, Ryu KH, et al. The effect of abdominal visceral fat, circulating inflammatory cytokines, and leptin levels on reflux esophagitis. J Neurogastroenterol Motil 2015;21:247-254.

14. Lee HL, Eun CS, Lee OY, et al. Association between erosive esophagitis and visceral fat accumulation quantified by abdominal CT scan. J Clin Gastroenterol 2009;43:240-243.

15. Chung SJ, Kim D, Park MJ, et al. Metabolic syndrome and visceral obesity as risk factors for reflux oesophagitis: a cross-sectional case-control study of 7078 Koreans undergoing health check-ups. Gut 2008;57:1360-1365.

16. Ze EY, Kim BJ, Kang H, Kim JG. Abdominal visceral to subcutaneous adipose tissue ratio is associated with increased risk of erosive esophagitis. Dig Dis Sci 2017;62:1265-1271.

17. Nam SY, Choi IJ, Ryu KH, Kim BC, Kim CG, Nam BH. Effect of Helicobacter pylori infection and its eradication on reflux esopha- 
gitis and reflux symptoms. Am J Gastroenterol 2010;105:21532162.

18. Maurovich-Horvat P, Massaro J, Fox CS, Moselewski F, O’Donnell CJ, Hoffmann U. Comparison of anthropometric, area- and vol- ume-based assessment of abdominal subcutaneous and visceral adipose tissue volumes using multi-detector computed tomography. Int J Obes (Lond) 2007;31:500-506. 